\title{
Phytopathology
}

\section{Prospects for Biological Soilborne Disease Control: Application of Indigenous Versus Synthetic Microbiomes}

\author{
Mark Mazzola and Shiri Freilich
}

First author: U.S. Department of Agriculture-Agricultural Research Service, Physiology and Pathology of Tree Fruits Research Laboratory, 1104 N. Western Avenue, Wenatchee, WA 98801; and second author: Agricultural Research Organization of Israel, Volcani Center, Bet Dagan, Israel. Accepted for publication 18 November 2016.

\begin{abstract}
Biological disease control of soilborne plant diseases has traditionally employed the biopesticide approach whereby single strains or strain mixtures are introduced into production systems through inundative/inoculative release. The approach has significant barriers that have long been recognized, including a generally limited spectrum of target pathogens for any given biocontrol agent and inadequate colonization of the host rhizosphere, which can plague progress in the utilization of this resource in commercial field-based crop production systems. Thus, although potential exists, this model has continued to lag in its application. New omics' tools have enabled more rapid screening of microbial populations allowing for the identification of strains with multiple functional attributes that may contribute to pathogen suppression. Similarly, these technologies also enable the characterization of consortia in natural systems which provide the framework for construction of synthetic microbiomes for disease control. Harnessing the potential of the microbiome indigenous to agricultural soils for disease suppression through application of specific management strategies has long been a goal of plant pathologists. Although this tactic also possesses limitation, our enhanced understanding of functional attributes of suppressive soil systems through application of community and metagenomic analysis methods provide opportunity to devise effective resource management schemes. As these microbial communities in large part are fostered by the resources endemic to soil and the rhizosphere, substrate mediated recruitment of diseasesuppressive microbiomes constitutes a practical means to foster their establishment in crop production systems.
\end{abstract}

The application of biological controls as a means to manage plant diseases, and in particular soilborne diseases, has been a continuing area of active research for numerous decades. As most commonly defined and practiced, inoculative or inundative biological disease control (Eilenberg et al. 2001) relies upon the purposeful introduction of living organisms to suppress the activity of plant pathogens. While perhaps real-world utility as a disease management alternative was the motivation for the initial exploration of this discipline, the field of biological disease control has inspired research and discovery well beyond the goal of attaining solutions or products for application in crop production systems. The argument can be made that the greatest utility of outcomes from research programs focused on biological control of soilborne plant diseases has been to inform our understanding of soil microbial ecology and identification of functional microbial entities and mechanisms by which saprophytic plant-associated microorganisms act to suppress diseases (Cook et al. 1995) and persist in soil environments (Jousset et al. 2006; Mazzola et al. 2009). Identifi-

Corresponding author: M. Mazzola; E-mail address: mark.mazzola@ars.usda.gov

This article is in the public domain and not copyrightable. It may be freely reprinted with customary crediting of the source. The American Phytopathological Society, 2017 cation of the diverse functional mechanisms contributing to the active plant pathogen suppression by microbial agents has been a hallmark of research in the field of biological control (Handelsman and Stabb 1996; Weller 1988). This knowledge provided the groundwork for subsequent screening and selection of potential biological agents for commercial application. This information has also been employed when predicting or clarifying the efficacy of a treatment or in attempts at understanding the functional attributes of suppressive soil that rely upon the activity of the indigenous soil microbiome (Hollister et al. 2013; Mazzola et al. 2015; Rosenzweig et al. 2012).

Although the use of biological controls for the management of soilborne diseases has long been a goal in sustainable agriculture, examples of successful application in commercial field-based crop production are limited. Discussions concerning the utilization of microbial inoculants for the biological control of soilborne diseases are commonly prefaced by a statement relative to its potential as a disease management strategy rather than a concrete statement of its effective implementation. As the seasons have changed, interest and excitement in the field of biological control has waxed and waned, but most recently has been resurrected in promotion of "engineered" or "synthetic" microbiomes for control of soilborne diseases. The question remains as to whether success can be derived from the application of biological disease control sensu stricto (i.e., distribution in the form of biopesticides) or whether successful use of biological 
control requires broader considerations to include methods that rely upon management of the endemic microbial resource in agricultural soil systems.

\section{LIMITS TO THE BIOPESTICIDE MODEL}

The historical study of disease-suppressive soils could be considered a major impetus for the myriad investigations that have examined the introduction of specific microbes into cropping systems as agents for the control of soilborne diseases (Cook and Baker 1983). The inoculative/inundative model of microbial introductions has been the most commonly employed in the field of biological disease control following on the paradigm utilized in the field of entomology (van Lenteren et al. 2003). However, the inherent biological complexity of soil systems has served as a challenge to the success of biological soilborne disease control, a feature that, in general, is not limiting to a similar degree in the domain of phyllosphere microbiology. The rapid decline in density of biocontrol organisms typically encountered after introduction to soil systems due to competitive interactions (Dupler and Baker 1984; Nihorimbere et al. 2011) may limit efficacy either through insufficient capacity to physically protect the plant or limits on generation of active metabolites which often are produced in a population density-dependent manner (Raaijmakers et al. 1999). Implementation of strategies to overcome such deficiencies, including repeated applications, are more easily integrated in aerial systems (e.g., fire blight control), but such efforts may continue to yield inconsistent results that are inferior to those attained with standard practices (Sundin et al. 2009). In the management of soilborne diseases, introduction of biological control agents in soils is commonly restricted to time of planting or limited to irrigated agriculture where repeated applications can be applied through use of a drip system (Selvaraj et al. 2014).

Considering the investments made in biological control research, one measure to illustrate success of the technology in the market place would include the number and spectrum of commercially available products. Given the breadth of research, the extent of bacterial and fungal genera comprising commercially formulated biological control agents is somewhat limited, including Ampelomyces, Bacillus, Coniothyrium, Paecilomyces, Phlebiopsis, Pseudomonas, Rhizobium, Serratia, Streptomyces, and Trichoderma (Berg 2009; Kawaguchi et al. 2012; Perez-Garcia et al. 2011) among others (Pertot et al. 2015). The market share for agricultural inoculants, representing plant growth promoting microorganisms, biocontrol agents and plant resistance stimulants, is projected to reach $\$ 437.1$ million by 2020 and growth in the market will be driven predominantly by increases in crop production relying upon organic farming practices (www.marketsandmarkets.com; as of 8.17.2016). This figure is dwarfed by the global crop protection chemicals market which is projected to reach $\$ 70.57$ billion by 2021 (www.marketsandmarkets.com; as of 8.17.2016).

Although traditionally limited to a specialized niche for application in conventional field-based agriculture, deployment of commercialized biological agents for disease control has significant usefulness for application in organic or protected crop production (Chandler et al. 2011; Paulitz and Bélanger 2001). These systems provide an opportunity either as a result of the limited availability of effective options for soilborne disease management or due to the system being more easily manipulated to optimize survival and activity of the introduced biocontrol organism. Regardless, reports continue to confer the possibility that biological disease control strategies that employ the inundative release model for such agents can be a viable approach in field based agricultural production while recognizing the significant barriers or limitations to successful use of the strategy (Marrone 2007; Pertot et al. 2015). In this context, a number of experimental limitations observed in the evaluation of biological disease control efficacy should raise caution relative to implementation of the approach as a practical replacement to traditional control methods in commercial agricultural production systems. Often times, appraisals of disease control success or failure lack critical field evaluation and/or comparisons are made to the level of crop disease observed in the absence of treatment rather than comparison with the control practice utilized in the commercial agricultural system, for example soil fumigation. Thus, while numerous biocontrol strains have been reported to demonstrate in vitro activity against soilborne pathogens and disease suppression under controlled conditions, commonly there has not been a corresponding level of accomplishment in the field. As an example, in vitro growth suppression of Fusarium oxysporum (Keel et al. 1992) and control of Fusarium wilt in multiple crop plants has been demonstrated in greenhouse trials in response to application of 2,4-DAPG-producing fluorescent Pseudomonas spp. (Kang 2012). Similarly, a diversity of antibiotic producing Streptomyces spp. have been identified, some from diseasesuppressive soils (Cha et al. 2016), with inhibitory activity toward F. oxysporum in different crop plant species (Cao et al. 2005; Kamal and Sharma 2014). In the majority of instances, the capacity of these agents to protect the plant over the course of a field growing season has not been attempted, with assessments limited to a greenhouse environment or a fraction of the expected cropping season duration.

When challenged to provide disease suppression over the course of a commercial growing season, single strain microbe introductions for management of diseases to which the plant host possesses an extended period of susceptibility consistently have failed to provide effective disease control under field conditions (Meyer et al. 2016). Similar outcomes can be quoted for a broad range of plant-pathogen systems for which season long protection of the susceptible host is desired if not required. A number of greenhouse and field experiments have examined the efficacy of Bacillus spp. as inoculants for the biological control of bacterial wilt incited by Ralstonia solanacearum. Invariably disease control attained in the greenhouse was superior to that in the field, with disease control failure a common occurrence in the field (Wei et al. 2011; Yuliar et al. 2015). In the context of the extended range of field studies reported, comparison at the field scale was not related to the plant performance in the absence of disease; thus, the economic significance of the findings is not clear.

The failure of introduced microbial agents to consistently and effectively provide biological control should not come as unexpected based upon the inherent requirements to attain soilborne disease suppression. The introduced strain must survive at potential infection sites over an extended period and effectively express attributes functional in disease control, some of which are energy demanding. In the absence of the plant, the organism must persist in a dormant phase in the resource limited bulk soil environment. The agent must also possess the capacity to rapidly alter its physiological state in transition to the rhizosphere niche (Blagodatskaya et al. 2014), where it is required to enter a rapid growth phase competing with endemic rapidly growing elements of the soil microbial community. In the absence of repeated introductions, the biocontrol agent is expected to compete in an ever changing environment with the myriad of organisms comprising the rhizosphere microbiome (Handelsman 2002) which inherently are ecologically well adapted to the specific soil/climatic conditions of a site. The demands placed on these introduced strains commonly result in a rapid decline in cell density. Population declines by orders of magnitude shortly after introduction into the soil environment, particularly for nonspore forming agents such as Pseudomonas spp., are commonly observed even in studies conducted under controlled environment conditions (Von Felten et al. 2010).

Effective rhizosphere populations and persistence of the population threshold required for disease control may vary with the targeted 
disease, the mode of action and the growth stage of the plant host (Picard et al. 2000). It is well established that population is not merely a matter of competitive exclusion but also may determine the expression of genes directly involved in the production of metabolites that determine disease control efficacy (Raaijmakers et al. 1999). Capacity of an introduced bacterium to persist in the rhizosphere and expression of functional traits may be influenced not only by competitive interactions with the soil biota but also vary with the plant host species or genotype. For instance, preferential persistence of rhizosphere inhabiting 2,4-DAPG-producing fluorescent pseudomonads was observed in a plant species or genotype-dependent manner (Landa et al. 2003; Mazzola et al. 2004). Significant differences in expression of the 2,4-DAPG biosynthetic gene phlA were detected in the rhizosphere of different cultivars of maize (Notz et al. 2001). Similarly, plant genotype could influence composition of the bacterial root endophyte community through differential phytohormone production (Lebeis et al. 2015). Despite these observations there is an absence of information regarding the attempt to marry these plant-microbe attributes in commercial development of biological controls.

\section{EXPANSION OF THE INTRODUCED MICROBIAL COMPLEX}

Given the complexity of soil microbiome-plant interactions, the limitation of the one strain-one pathogen approach to biological soilborne disease control should not be an unexpected finding. In the same vein of reasoning, this complexity argues for an approach that examines a "community perspective" even one as narrowly defined by a multiplicity of introduced microorganisms with perhaps different modes of action. The advent of studies in the realm of soil and plant microbiomes has led to a resurgence in the study of "synthetic Phytobiomes" (Rolshausen et al. 2015) or "synthetic communities" and the capacity to regulate formation of such communities (Lebeis et al. 2015) for plant disease control. The introduction of multiple biological control agents possessing multiple mechanisms of action or possessing varied ecological requirements and niches is not a new strategy (Duffy et al. 1996; Xu et al. 2011). However, the advanced capacity to characterize the phytobiome through the application of high throughput nextgeneration sequencing technologies has potential to advance our ability to strategically select for agents that have unique host sitespecific qualities that function in biological disease control. For instance, among a collection Pseudomonas fluorescens strains representing a single operational taxonomic units, endosphere strains were enriched in pathways involving attributes such as root growth promotion relative to rhizosphere strains (Timm et al. 2015). These strains also possessed an increased metabolic range consistent with colonization of the endosphere, a characteristic that could enable improved strain persistence and thus enhanced disease control. This same endophytic community possesses the potential advantage of a greater intimacy with the plant host relative to rhizosphere-inhabiting biocontrol agents, resulting in more stable interactions with plants than rhizosphere-inhabiting microbes (Compant et al. 2010; Malfanova et al. 2011; Ryan et al. 2008). In commercial agriculture, application of endophytes for disease control is likely to have superior success in systems utilizing transplants where growing stock may be treated prior to establishment in the field rather than depending on soil inoculants requiring subsequent root colonization and host penetration. Although new technologies expand our abilities to examine the complexity, modes of action, and site-specific residence of microbes with disease control potential, the synthesis of this knowledge into a functional and transferable microbiome for commercial application will face significant challenges. Certain obstacles are consistent with those encountered in traditional biological control such as establishment of the functional biology in a highly competitive potentially nonnative ecosystem.

Next generation sequencing technology can also be utilized to screen for biological entities possessing a multiplicity of attributes known to function in pathogen suppression. Historically, such screening has involved the examination of phenotypes in a singular fashion to determine the spectrum of activity the organism may possess in expressing biological control potential. Subsequently, extensive analyses were required to determine the mode(s) of action the organism utilized to suppress the targeted pathogen. Whole genome sequencing has enabled the prediction of traits possessed by the organism that may have action toward the target pathogen (Loper et al. 2012). Comparative genomics can be utilized in concert with high-throughput assays for optimizing selection of candidate strains for evaluation in development of biological control agents (Inch et al. 2016). Genome mining may also yield new discoveries regarding potential for microbial production of novel metabolites with antimicrobial activity (Scheffler et al. 2013).

The identification of multistrain or multimechanistic options for biological disease control will continue to face challenges for implementation, not the least of which is commercialization of the resource. The limited cropping systems or spectrum of efficacy across pathogens for which any biocontrol product functions will continue to hinder investment in product development. Alternatively, regulatory action or treaty relative to application of certain chemical approaches, such as removal or limits on use of specific fumigant chemistries from the marketplace (California Department of Pesticide Regulation 2013; United Nations Environment Programme 2012; United States Department of State 2014) may act to elevate prolonged interest in commercialization and utilization of biologicals independently or in integrated disease management approaches (Pertot et al. 2015). Beyond availability of product, major hurdles to the use of biological controls for effective soilborne disease control in field-level crop production systems exist. However, there are multiple avenues that may be pursued to extract the utility of this disease management approach in commercial agriculture. One such possibility is to recognize the limits of the methodology and to employ the resource in systems or environments where a positive outcome is achievable (Pertot et al. 2015). While a simple and inherently obvious statement, it is not a strategy that has consistently been pursued.

\section{CREATING SYSTEM OPPORTUNITIES FOR SUCCESSFUL INTRODUCTION OF BIOLOGICAL CONTROLS}

There is a fundamental value in the use of microbial introductions as a means to provide biological disease control based upon the general lack of options in organic production systems or for use in integrated disease control programs. While true, the directions for which to employ such a strategy with plausible benefit are not as obvious. For instance, it has been suggested that implementation of perturbations to the soil environment could be used as a means to establish a niche more suitable for effective establishment of a biological control agent. One such example was to use biocontrol agents in concert with anaerobic soil disinfestation (ASD) or "biofumigation" (Pertot et al. 2015). This design would intimate the view that ASD or biofumigation leads to a soil system possessing a less diverse, diminished competitive environment through chemical suppression of the resident microbiome, thus providing opportunity for the introduction of nonnative strains. Studies indicate that these treatments generate a soil microbiome possessing reduced diversity (Hewavitharana and Mazzola 2016; Mazzola et al. 2015); however, disease control in both systems has been shown to function through a multiplicity of mechanisms (Hewavitharana et al. 2014) including 
dependence on activity of the rhizosphere/soil microbiome (Weerakoon et al. 2012). Selective enrichment of endemic bacterial and fungal phyla are observed in both systems (Hewavitharana and Mazzola 2016; Mazzola et al. 2015), including commonly recognized biological control agents such as Trichoderma spp. (Weerakoon et al. 2012), Streptomyces spp. (Cohen et al. 2005), and Bacillus spp. (Stremińska et al. 2014). These biological transformations not only are associated with disease suppression but may create a biological environment that is even more resistant to invasion by introduced agents than the nontreated soil system (Fig. 1).

Capacity to integrate biological controls with these methods through enhanced microbial persistence cannot be assumed, and would require a more complete understanding of microbial agents with potential to benefit from such modified systems. In the biofumigation model, soil incorporation of specific mustard residue amendments (e.g., seed meal of Brassica juncea) results in generation of allyl isothiocyanate. Certain fungi, including Trichoderma spp. possess tolerance to this chemistry and proliferate in soils treated with B. juncea seed meal (Weerakoon et al. 2012). This environment may provide an opportunity to more effectively establish and utilize Trichoderma-based biological controls. Similarly, ASD conducted using specific carbon inputs can result in selective amplification of bacterial groups, such as the Firmicutes (Stremińska et al. 2014), which possess elements previously reported as effective biological control agents, including Bacillus spp. (Kloepper et al. 2004; Smith et al. 1993). Mating the desired microbial agent for introduction with the appropriate perturbation event will be instrumental in determining the capacity of this approach to achieve enhanced establishment of biological control strains in the soil environment.

Soil solarization is a well-studied method for use in the control of soilborne plant diseases with efficacy resulting, in part, due to thermal inactivation of the pathogen (Katan 1981). Elevated soil temperatures achieved during solarization afford an alternative disturbance that may be exploited to extend persistence of introduced biological control agents into crop soil systems. Reduced or altered competitive relationships realized in a solarized soil system posttreatment may enable more rapid and consistent establishment of biological agents. The fast growing Pseudomonadaceae recover quickly in solarized or heat treated soils (van der Voort et al. 2016) and are found at higher densities in the rhizosphere of plants grown in solarized compared with nonsolarized soils (Gamliel and Katan 1991). Correspondingly, persistence of plant growth-promoting fluorescent Pseudomonas spp. applied as a radish seed treatment increased root colonization on average $3.5 \times$ in solarized soil compared with nonsolarized control soil (Stapleton and DeVay 1984). Alternatively, opportunity may exist for successful application of heat-tolerant bacterial families such as Actinobacteria, Bacillaceae, and Paenibacillaceae (Stapleton and DeVay 1982; van der Voort et al. 2016) during the process of solarizing field soils.

\section{MANAGEMENT OF THE NATIVE SOIL MICROBIOME FOR BIOLOGICAL CONTROL}

Functional biological controls, beyond the convention of augmentative introductions, have been documented repeatedly in agricultural ecosystems. In terms of soilborne disease control, such actualities are evidenced in the form of disease-suppressive soils, which commonly are dependent upon the activity of the resident soil microbial community (Weller et al. 2002). Disease suppression may operate through competitive interactions among broad elements of the soil microbiome to diminish overall pathogen activity, commonly referred to as general suppression (Cook and Baker 1983). Alternatively, the suppressive activity may be operative in a more defined manner toward a specific pathogen and involving the action of a distinct subset of the soil microbiome (Berendsen et al. 2012; Mendes et al. 2011). Given the apparent existence of common attributes for suppressive systems for a given pathogen (Weller et al. 2002), management of the microbiological resources endemic to a soil may be a means to more effectively yield biological disease control. Augmentation of microbial consortia indigenous to a soil system for biological disease control requires significant knowledge of functional attributes, factors regulating their activity, and complexity of the plant-microbe and microbe-microbe interactions, some of which may be attained through previous and ongoing study of disease-suppressive soils (Chapelle et al. 2015; Kinkel et al. 2012).

The institution of practices promoting the assembly of a diseasesuppressive soil microbiome in a cropping system would intuitively possess advantages over the introduction of nonnative organisms. Several approaches have been utilized in attempt to drive successional changes in the soil microbiome toward development
FIGURE 1

Relative growth performance of 'Gala' apple on M.9 rootstock during the second growing season on a replant orchard site

when cultivated in (left to right) 1,3dichloropropene/chloropicrin fumigated, Brassica juncea/Sinapis alba seed meal amended $\left(6.6 \mathrm{t} \mathrm{ha}^{-1}\right)$ or nontreated replant orchard soil (Mazzola et al. 2015). Seed

meal soil amendment produced a soil microbiological environment that was resistant to re-infestation by apple root pathogens including Pratylenchus penetrans and Pythium spp. In contrast, fumigated soils were rapidly recolonized by these pathogens and although suppressed in the initial growing season, their densities were not different from the control soil at the end of the second growth season.

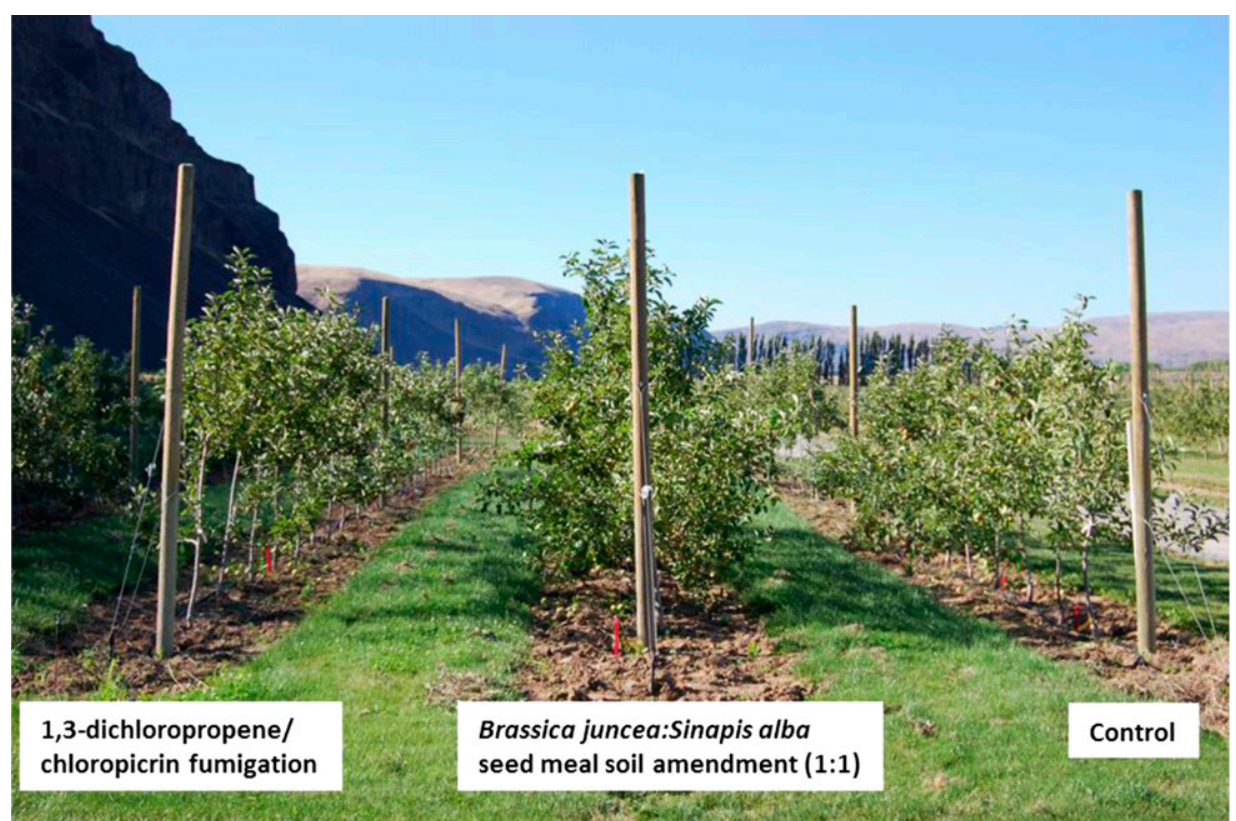


of a suppressive microbial consortium. With or without prior awareness of the circumstance, in all probability these efforts have employed substrate-specific attributes of an input to recruit microbial elements with the capacity to limit disease development. Development of disease suppression in response to organic substrate inputs has been a repeatedly observed phenomenon (Stone et al. 2004) even though biotic or abiotic factors contributing to the response may not have been recognized. For instance, Brassica seed meal amendments selectively amplify populations of Streptomyces spp. having capacity to suppress disease incited by Rhizoctonia solani through induction of host defense responses (Cohen et al. 2005). The seed meals derived from Brassicas were previously used as a feedstock in commercial production of Streptomyces spp. due to the extensive repertoire of extracellular enzymes possessed by these bacteria which enable to effectively utilize the seed meal as a substrate (Brabban and Edwards 1996). Likewise, induction of soil suppressiveness toward Rosellinia necatrix in response to soil incorporation of composted almond shells was dependent upon evolution in composition of the soil microbiome (Vida et al. 2016). Various organic inputs, in the form of amendments, green manures, and cover crops, are extensively utilized in organic agricultural systems for soilborne disease management (van Bruggen and Finckh 2016). The general perception in use of these inputs is that a more diverse microbiome with elevated activity is derived from employment of these tactics resulting in a more resilient system capable of suppressing soilborne diseases (Van Bruggen and Finckh 2016). However, in the majority of instances the biological attributes responsible for disease suppression and the capacity to predictably transfer the approach to other sites, have rarely been examined in these systems. Likewise, it cannot be expected that development of biological suppression to one organism will forecast efficacy toward the diverse spectrum of pathology to which a plant root system is exposed. Thus, in a multiyear replicated apple orchard field trial, although suppression of Pythium spp. root infection was observed in organic relative to conventionally managed blocks, root infection by Rhizoctonia spp. was higher under the organic management system (Mazzola et al. 2002).

Beyond the addition of bio-based or alternative soil inputs, the plant, through the excretion of metabolites into the rhizosphere, is a dominant source of substrate with potential to direct the development of the soil microbiome (Broeckling et al. 2008; Hartmann et al. 2009). Application of specific phytochemicals to a soil system demonstrated capacity to deter or stimulate specific operational taxonomic groups (bacteria) and mixtures of these metabolites could act synergistically to promote groups of bacteria (Badri et al. 2013). Compositional framework of the metabolite profile expressed by plant roots may differ significantly even among genotypes of the same species. As such, structure of the rhizosphere microbiome is likely to be determined in a plant species or even genotype-dependent manner. Comparison of bacterial communities demonstrated that plant host and its corresponding root exudates shape community structure in the rhizosphere (Achouak and Haichar 2013) At a more detailed level, analysis of maize inbred lines cultivated under field conditions provided evidence of heritable variation in rhizosphere microbial community composition (Peiffer et al. 2013). Abundance and genotypes of pathogen suppressive bacteria possessing a specific functional attribute were found to be recruited to the rhizosphere in a plant-cultivar dependent manner (Mazzola et al. 2004). This finding indicated the potential importance of host genotype in determining efficacy of strategies that seek to promote functional biological disease control by managing the indigenous soil microbiology.

Recent findings in the application of Brassica seed meal derived plant disease control and growth promotion of apple on orchard replant sites support this premise. Seed meal derived soilborne disease control has been shown to function, in part, through modification of the soil microbiome (Cohen et al. 2005; Weerakoon et al. 2012). Seed meal amendment induces significant changes in the soil microbiome in an application rate-dependent manner (Mazzola and Wang 2015). However, changes in composition of both the bacterial and fungal rhizosphere community for apple trees grown in these soils was dependent upon rootstock genotype. Significant transformation of the rhizosphere microbiome occurred at lower seed meal rates for G.210 rootstock than MM.106 rootstock and corresponded with relative disease control achieved.

\section{CURRENT LIMITS IN THOUGHT AND PRACTICE TO INDUCED BIOLOGICAL CONTROL}

The argument can be made that use of input strategies to foster development of biologically mediated soilborne disease control suffers, in some degree, from the same limitations in predicting effective outcomes as biological controls applied using the inundative release strategy (Kinkel et al. 2012). Although recent studies employing next-generation sequence analysis have effectively outlined changes in the soil microbiome associated with disease suppression in response to a management practice, there has been an absence of analysis concerning the evolutionary processes that ultimately yield composition of the effective microbiome. In addition, as outlined and discussed by Poudel et al. (2016), conclusions reached may fail to take into account the myriad interactions among elements of the microbiome that act in concert to determine disease suppression. A combination of horticultural, ecological, and computational approaches need to be employed to address the above challenges and promote the development of robust approaches for the educated design of specific strategies in manipulation of the soil microbiome for soilborne disease control.

\section{OPPORTUNITY TO PROMOTE ASSEMBLY OF SUPPRESSIVE MICROBIOME}

Success of a substrate-based treatment to stimulate a microbiomemediated disease control strategy will be determined by the introduction of accessible metabolites that are beneficial to organisms functional in disease control or deleterious to organisms contributing to disease progression. Metagenomic surveys allow exploring the significance of shifts in community structure through comparing the functional potential of different samples. In particular, metabolic network approaches provide a framework for translating discrete data from ecological samples into a structured view of biological functions and the subsequent conductance of simulations exploring the associations between environment (resources dominant in a specific amendment treatment) and community (species forming possible metabolic conversions repertoire) (Noecker et al. 2016; Ponomarova and Patil 2015; Widder et al. 2016). Similar to genomic approaches where species-specific metabolic networks are constructed based on the content of enzyme coding genes, community networks can be constructed based on the functional annotations of metagenomics data (Abubucker et al. 2012; Levy and Borenstein 2013; Levy et al. 2015; Roume et al. 2015; Zelezniak et al. 2016). Beyond the static representation of data as a network, computational simulations dynamically address the influence of environmental inputs (nutritional resources) or the functional repertoire of the community (species/genomic content in the sample) on network structure and composition. At the species (genome) level, such simulations allowed predicting the effects of genetic and environmental perturbations on the network and thus on the genome (Freilich et al. 2009, 2010; Oberhardt et al. 2009). At the community level, a similar approach can be applied for delineating food-chains and nutritional dependencies in complex communities, allowing formulating predictions for the educated induction for a predefined community shift (Widder et al. 2016). Such integration of metagenomics data will lay foundations for the educated design of 
sustainable solutions for suppressing soilborne disease symptoms through substrate mediated recruitment of disease-suppressive microbiomes in cropping systems.

\section{PARTING PERSPECTIVE}

In its many forms, biological disease control of soilborne diseases continues to possess more potential as a prospective strategy for use in field-level agricultural production systems than a method whose implementation is utilized without reservation. The barriers and limitations to use of the biopesticide model of biological control have long been recognized and described including narrow product markets and higher costs relative to chemical alternatives. While there is a general desire among the public for use of biological controls in crop production, this has generated an uneven, and until recently tepid, investment in commercial production of viable biological controls. Recent and proposed regulatory actions concerning pesticide use is likely to offer continued motivation for such investment. Alternatively, management of the indigenous soil microbial community, though also possessing limitation, would appear to provide a more sustainable means to meet the goal of biological soilborne disease control. The technological advances deemed necessary to attain progress toward characterizing the organismal interactions and community functions in biological control (Handelsman 2002) are now broadly available. Thus, the challenge for development of successful strategies for use of the indigenous microbiome for biological control of soilborne diseases will continue to require interactions among a diverse corps of scientific interests.

\section{LITERATURE CITED}

Abubucker, S., Segata, N., Goll, H., Schubert, A. M., Izard, J., Cantarel, B. L., Rodriguez-Mueller, B., Zucker, J., Thiagarajan, M., Henrissat, B., White, O., Kelley, S. T., Methé, B., Schloss, P. D., Gevers, D., Mitreva, M., and Huttenhower, C. 2012. Metabolic reconstruction for metagenomics data and its application to the human microbiome. PLoS Comput. Biol. 8:e1002358.

Achouak, W., and Haichar, F. E. 2013. Shaping of microbial community structure and function in the rhizosphere by four diverse plant species. Pages 161-167 in: Molecular Microbial Ecology of the Rhizosphere. F. J. de Bruijn, ed. Vol. 1 and 2. John Wiley \& Sons, Inc., Hoboken, NJ.

Badri, D. V., Chaparro, J. M., Zhang, R., Shen, Q., and Vivanco, J. M. 2013. Application of natural blends of phytochemicals derived from the root exudates of Arabidopsis to the soil reveal that phenolic-related compounds predominantly modulate the soil microbiome. J. Biol. Chem. 288:45024512.

Berendsen, R. L., Pieterse, C. M., and Bakker, P. A. 2012. The rhizosphere microbiome and plant health. Trends Plant Sci. 17:478-486.

Berg, G. 2009. Plant-microbe interactions promoting plant growth and health: Perspectives for controlled use of microorganisms in agriculture. Appl. Microbiol. Biotechnol. 84:11-18.

Blagodatskaya, E., Blagodatsky, S., Anderson, T.-H., and Kuzyakov, Y. 2014. Microbial growth and carbon use efficiency in the rhizosphere and root free soil. PLoS ONE 9:e93282.

Brabban, A. D., and Edwards, C. 1996. Characterization of growth and product formation by a thermophilic streptomycete grown in a particulate rape meal-derived liquid medium. J. Appl. Bacteriol. 80:651-658.

Broeckling, C. D., Broz, A. K., Bergelson, J., Manter, D. K., and Vivanco, J. M. 2008. Root exudates regulate soil fungal community composition and diversity. Appl. Environ. Microbiol. 74:738-744.

California Department of Pesticide Regulation. 2013. Nonfumigant Strawberry Production Working Group Action Plan. Page 40. Published online. http:// www.cdpr.ca.gov/docs/pestmgt/strawberry/work_group/action_plan.pdf

Cao, L., Qiu, Z., You, J., Tan, H., and Zhou, S. 2005. Isolation and characterization of endophytic streptomycete antagonists of Fusarium wilt pathogen from surface-sterilized banana roots. FEMS Microbiol. Lett. 247: 147-152.

Cha, J.-Y., Han, S., Hong, H.-J., Cho, H., Kim, D., Kwon, Y., Kwon, S.-K., Crusemann, M., Lee, Y. B., Kim, J. F., Giaever, G., Nislow, C., Moore, B. S., Thomashow, L. S., Weller, D. M., and Kwak, Y.-S. 2016. Microbial and biochemical basis of a Fusarium wilt-suppressive soil. ISME J. 10: 119-129.
Chandler, D., Bailey, A. S., Tatchell, G. M., Davidson, G., Greaves, J., and Grant, W. P. 2011. The development, regulation and use of biopesticides for integrated pest management. Philos. Trans. R. Soc. Lond. B Biol. Sci. 366: 1987-1998.

Chapelle, E., Mendes, R., Bakker, P. A. H. M., and Raaijmakers, J. M. 2015. Fungal invasion of the rhizosphere microbiome. ISME J. 10:265-268.

Cohen, M. F., Yamasaki, H., and Mazzola, M. 2005. Brassica napus seed meal soil amendment modifies microbial community structure, nitric oxide production and incidence of Rhizoctonia root rot. Soil Biol. Biochem. 37: 1215-1227.

Compant, S., Clement, C., and Sessitsch, A. 2010. Plant growth-promoting bacteria in the rhizo- and endosphere of plants: Their role, colonization, mechanisms involved and prospects for utilization. Soil Biol. Biochem. 42: 669-678.

Cook, R. J., and Baker, K. F. 1983. The Nature and Practice of Biological Control of Plant Pathogens. The American Phytopathological Society, St. Paul, MN.

Cook, R. J., Thomashow, L. S., Weller, D. M., Fujimoto, D., Mazzola, M., Bangera, G., and Kim, D.-S. 1995. Molecular mechanisms of defense by rhizobacteria against root disease. Proc. Natl. Acad. Sci. USA 92:41974201.

Duffy, B. K., Simon, A., and Weller, D. M. 1996. Combination of Trichoderma koningii with fluorescent pseudomonads for control of take-all on wheat. Phytopathology 86:188-194.

Dupler, M., and Baker, R. 1984. Survival of Pseudomonas putida, a biological control agent, in soil. Phytopathology 74:195-200.

Eilenberg, J., Hajek, A., and Lomer, C. 2001. Suggestions for unifying the terminology in biological control. BioControl 46:387-400.

Freilich, S., Kreimer, A., Borenstein, E., Gophna, U., Sharan, R., and Ruppin, E. 2010. Decoupling environment-dependent and independent genetic robustness across bacterial species. PLoS Comput. Biol. 6:e1000690.

Freilich, S., Kreimer, A., Borenstein, E., Yosef, N., Sharan, R., Gophna, U., and Ruppin, E. 2009. Metabolic-network-driven analysis of bacterial ecological strategies. Genome Biol. 10:R61.

Gamliel, A., and Katan, J. 1991. Involvement of fluorescent pseudomonads and other microorganisms in increased growth response of plants in solarized soils. Phytopathology 81:494-502.

Handelsman, J. 2002. Future trends in biocontrol. Biological Control of Crop Diseases. S. S. Gnanamanickam, ed. CRC Press, Boca Raton, FL.

Handelsman, J., and Stabb, E. V. 1996. Biocontrol of soilborne plant pathogens. Plant Cell 8:1855-1869.

Hartmann, A., Schmid, M., van Tuinen, D., and Berg, G. 2009. Plant driven selection of microbes. Plant Soil 321:235-257.

Hewavitharana, S. S., and Mazzola, M. 2016. Carbon source-dependent effects of anaerobic soil disinfestation on soil microbiome and suppression of Rhizoctonia solani AG-5 and Pratylenchus penetrans. Phytopathology 106: 1015-1028.

Hewavitharana, S. S., Rudell, D., and Mazzola, M. 2014. Carbon sourcedependent antifungal and nematicidal volatiles derived during anaerobic soil disinfestation. Eur. J. Plant Pathol. 140:39-52.

Hollister, E. B., Hu, P., Wang, A. S., Hons, F. M., and Gentry, T. J. 2013. Differential impacts of bassicaceous and nonbrassicaceous oilseed meals on soil bacterial and fungal communities. FEMS Microbiol. Ecol. 83: 632-641.

Inch, S., Leder, J., Taylor, A., Frodyma, M., Furlan, M., Schulte, M., Berka, R., Maranta, M., Cherry, B., and Prusinkiewicz, E. 2016. Evaluation of microbials using comparative genomics and high-throughput assays as a method to reduce product development time. (Abstr.) Phytopathology 106 (suppl.):S4.168.

Jousset, A., Lara, E., Wall, L. G., and Valverde, C. 2006. Secondary metabolites help biocontrol strain Pseudomonas fluorescens $\mathrm{CHA} 0$ to escape protozoan grazing. Appl. Environ. Microbiol. 72:7083-7090.

Kamal, R., and Sharma, A. K. 2014. Control of Fusarium wilt using biological agent Streptomyces sp. CPP-53 isolated from compost with plant growth promoting effect on tomato under greenhouse condition. J. Microbiol. Antimicrob. 6:97-103.

Kang, B. R. 2012. Biocontrol of tomato Fusarium wilt by a novel genotype of 2,4-diacetylphloroglucinol-producing Pseudomonas sp. NJ134. Plant Pathol. J. 28:93-100.

Katan, J. 1981. Solar heating (solarization) control of soilborne pests. Annu. Rev. Phytopathol. 19:211-236.

Kawaguchi, A., Kondo, K., and Inoue, K. 2012. Biological control of apple crown gall by nonpathogenic Rhizobium vitis strain $\mathrm{VAR}_{03-1}$. J. Gen. Plant Pathol. 78:287-293.

Keel, C., Schnider, U., Maurhofer, M., Voisard, C., Laville, J., Burger, U., Wirthner, P., Haas, D., and Defago, G. 1992. Suppression of root diseases by Pseudomonas fluorescens CHA0: Importance of the bacterial secondary metabolite 2,4-diacetylphloroglucinol. Mol. Plant-Microbe Interact. 5:4-13. 
Kinkel, L. L., Schlatter, D. C., Bakker, M. G., and Arenz, B. E. 2012. Streptomyces competition and co-evolution in relation to plant disease suppression. Res. Microbiol. 163:490-499.

Kloepper, J. W., Ryu, C. M., and Zhang, S. 2004. Induce systemic resistance and promotion of plant growth by Bacillus spp. Phytopathology 94: 1259-1266.

Landa, B. B., Mavrodi, D. M., Thomashow, L. S., and Weller, D. M. 2003. Interactions between strains of 2,4-diacetylphloroglucinol-producing Pseudomonas fluorescens in the rhizosphere of wheat. Phytopathology 93:982-994.

Lebeis, S. L., Paredes, S. H., Lundberg, D. S., Breakfield, N., Gehring, J., McDonald, M., Malfatti, S., del Rio, T. G., Jones, C. D., Tringe, S. G., and Dangl, J. L. 2015. Salicylic acid modulates colonization of the root microbiome by specific bacterial taxa. Science $349: 860-864$.

Levy, R., and Borenstein, E. 2013. Metabolic modeling of species interaction in the human microbiome elucidates community-level assembly rules. Proc. Natl. Acad. Sci. USA 110:12804-12809.

Levy, R., Carr, R., Kreimer, A., Freilich, S., and Borenstein, E. 2015. NetCooperate: A network-based tool for inferring host-microbe and microbe-microbe cooperation. BMC Bioinformatics 16:164.

Loper, J. E., Hassan, K. A., Mavrodi, D. V., Davis, E. W., Lim, C. K., Shaffer, B. T., Elbourne, L. D. H., Stockwell, V. O., Hartney, S. L., Breakwell, K., Henkels, M. D., Tetu, S. G., Rangel, L. I., Kidarsa, T. A., Wilson, N. L., van de Mortel, J. E., Song, C., Blumhagen, R., Radune, D., Hostetler, J. B., Brinkac, L. M., Kluepfel, D. A., Wechter, W. P., Anderson, A. J., Kim, Y. C., Pierson, L. S., Pierson, E. A., Lindow, S. E., Kobayashi, D. Y., Raaijmakers, J. M., Weller, D. M., Thomashow, L. S., Allen, A. E., and Paulsen, I. T. 2012. Comparative genomics of plant-associated Pseudomonas spp.: Insights into diversity and inheritance of traits involved in multitrophic interactions. PLoS Genet. 8:e1002784.

Malfanova, N., Kamilova, F., Validov, S., Shcherbakov, A., Chebotar, V., Tikhonovich, I., and Lugtenberg, B. 2011. Characterization of Bacillus subtilis $\mathrm{HC} 8$, a novel plant-beneficial endophytic strain from giant hogweed. Microbiol. Biotechnol. 4:523-532.

Marrone, P. G. 2007. Barriers to adoption of biological control agents and biological pesticides. CAB Reviews: Perspectives in Agriculture, Veterinary Science, Nutrition and Natural Resources. CABI, Wallingford, UK.

Mazzola, M., Andrews, P. K., Reganold, J. P., and Lévesque, C. A. 2002. Frequency, virulence, and metalaxyl sensitivity of Pythium spp. isolated from apple roots under conventional and organic production systems. Plant Dis. 86:669-675.

Mazzola, M., de Bruijn, I., Cohen, M. F., and Raaijmakers, J. M. 2009. Protozoan-induced regulation of cyclic lipopeptide biosynthesis is an effective predation defense mechanism for Pseudomonas fluorescens. Appl. Environ. Microbiol. 75:6804-6811.

Mazzola, M., Funnell, D. L., and Raaijmakers, J. M. 2004. Wheat cultivarspecific selection of 2,4-diacetylphloroglucinol-producing fluorescent Pseudomonas species from resident soil populations. Microbiol. Ecol. 48: 338-348.

Mazzola, M., Hewavitharana, S., and Strauss, S. L. 2015. Brassica seed meal soil amendments transform the rhizosphere microbiome and improve apple production though resistance to pathogen re-infestation. Phytopathology 105:460-469.

Mazzola, M., and Wang, L. 2015. Reduced rate seed meal amendment efficacy is plant genotype-dependent. Page 14.1 in: Proceedings, Annual International Research Conference on Methyl Bromide Alternatives and Emissions Reductions, San Diego, CA.

Mendes, R., Kruijt, M., de Bruijn, I., Dekkers, E., van der Voort, M., Schneider, J. H. M., Piceno, Y. M., DeSantis, T. Z., Andersen, G. L., Bakker, P. A. H. M., and Raaijmakers, J. M. 2011. Deciphering the rhizosphere microbiome for disease-suppressive bacteria. Science 332: 1097-1100.

Meyer, S. L., Everts, K. L., McSpadden Gardener, B., Masler, E. P., Abedelnabby, H. M. E., and Skantar, A. M. 2016. Assessment of DAPGproducing Pseudomonas fluorescens for management of Meloidogyne incognita and Fusarium oxysporum on watermelon. J. Nematol. 48:43-53.

Nihorimbere, V., Ongena, M., Smargiassi, M., and Thonart, P. 2011. Beneficial effect of the rhizosphere microbial community for plant growth and health. Biotechnol. Agron. Soc. Environ. 15:327-337.

Noecker, C., Eng, A., Srinivasan, S., Theriot, C. M., Young, V. B., Jansson, J. K., Fredricks, D. N., and Borenstein, E. 2016. Metabolic model-based integration of microbiome taxonomic and metabolomic profiles elucidates mechanistic links between ecological and metabolic variation. mSystems 1:e00013-15. doi:10.1128/mSystems.00013-15

Notz, R., Maurhofer, M., Schnider-Keel, U., Duffy, B., Haas, D., and Défago, G. 2001. Biotic factors affecting expression of the 2,4-diacetylphloroglucinol biosynthesis gene phlA in Pseudomonas fluorescens biocontrol strain CHA0 in the rhizosphere. Phytopathology 91:873-881.
Oberhardt, M. A., Palsson, B. Ø., and Papin, J. A. 2009. Applications of genome-scale metabolic reconstructions. Mol. Syst. Biol. 5:320.

Paulitz, T. C., and Bélanger, R. R. 2001. Biological control in greenhouse systems. Annu. Rev. Phytopathol. 39:103-133.

Peiffer, J. A., Spor, A., Koren, O., Zhao, J., Tringe, S. G., Dangl, J. L., Buckler, E. S., and Ley, R. E. 2013. Diversity and heritability of the maize rhizosphere microbiome under field conditions. Proc. Natl. Acad. Sci. USA 110: 6548-6553.

Perez-Garcia, A., Romero, D., and de Vicente, A. 2011. Plant protection and growth stimulation by microorganisms: Biotechnological applications of Bacilli in agriculture. Curr. Opin. Biotechnol. 22:187-193.

Pertot, I., Alabouvette, C., Esteve, E. H., and Franca, S. 2015. Mini-paper: The use of microbial biocontrol agents against soil-borne diseases. Published online by The Agricultural European Innovation Partnership. http:// ec.europa.eu/eip/agriculture/sites/agri-eip/files/8_eip_sbd_mp_biocontrol_ final.pdf

Picard, C., Di Cello, F., Ventura, M., Fani, R., and Guckert, A. 2000. Frequency and biodiversity of 2,4-diacetylphloroglucinol producing bacteria isolated from the maize rhizosphere at different stages of plant growth. Appl. Environ. Microbiol. 66:948-955.

Ponomarova, O., and Patil, K. R. 2015. Metabolic interactions in microbial communities: Untangling the Gordian knot. Curr. Opin. Microbiol. 27: 37-44.

Poudel, R., Jumpponen, D. C., Paulitz, T. C., McSpadden Gardener, B. B., Kinkel, L. L., and Garrett, K. A. 2016. Microbiome networks: A systems framework for identifying candidate microbial assemblages for disease management. Phytopathology 10:1083-1096.

Raaijmakers, J. M., Bonsall, R. F., and Weller, D. M. 1999. Effect of population density of Pseudomonas fluorescens on production of 2,4diacetylphloroglucinol in the rhizosphere of wheat. Phytopathology 89: 470-475.

Rolshausen, P. E., Yan, J. I., Ruegger, P., Borneman, J., and Roper, C. 2015. The grape endophytic microbiome and its impact on Pierce's disease development. (Abstr.) Phytopathology 105(suppl.):S4.172.

Rosenzweig, N., Tiedje, J. M., Quensen, J. F., III, Meng, Q., and Hao, J. J. 2012. Microbial communities associated with potato common scab suppressive soil determined by pyrosequencing analyses. Plant Dis. 96:718-725.

Roume, H., Heintz-Buschart, A., Muller, E. E. L., May, P., Satagopam, V. P., Laczny, C. C., Narayanasamy, S., Lebrun, L. A., Hoopmann, M. R. Schupp, J. M., Gillece, J. D., Hicks, N. D., Engelthaler, D. M., Sauter, T., Keim, P. S., Moritz, R. L. and Wilmes, P. 2015. Comparative integrated omics: Identification of key functionalities in microbial community-wide metabolic networks. npj Biofilms Microbiomes 1:15007.

Ryan, R. P., Germaine, K., Franks, A., Ryan, D. J., and Dowling, D. N. 2008. Bacterial endophytes: Recent developments and applications. FEMS Microbiol. Lett. 278:1-9.

Scheffler, R. J., Colmer, S., Tynan, H., Demain, A. L., and Gullo, V. P. 2013. Antimicrobials, drug discovery and genome mining. Appl. Microbiol. Biotechnol. 97:969-978.

Selvaraj, S., Ganeshamoorthi, P., Anand, T., Raguchander, T., Seenivasan, N., and Samiyappan, R. 2014. Evaluation of a liquid formulation of Pseudomonas luorescens against Fusarium oxysporum f. sp. cubense and Helicotylenchus multicinctus in banana plantation. BioControl 59:345-355.

Smith, K. P., Havey, M. J., and Handelsman, J. 1993. Suppression of cottony leak of cucumber with Bacillus cereus strain UW85. Plant Dis. 77:139-142.

Stapleton, J. J., and DeVay, J. E. 1982. Effect of soil solarization on populations of selected soilborne microorganisms and growth of deciduous fruit tree seedlings. Phytopathology 72:323-326.

Stapleton, J. J., and DeVay, J. E. 1984. Thermal components of soil solarization as related to changes in soil and root microflora and increased plant growth response. Phytopathology 74:255-259.

Stone, A. G., Scheuerell, S. J., and Darby, H. M. 2004. Suppression of soilborne diseases in field agricultural systems:organic matter management, cover cropping, and other cultural practices. Pages 131-177 in: Soil Organic Matter in Sustainable Agriculture. F. Magdoff and R. R. Well, eds. CRC Press, Boca Ratón, FL.

Stremińska, M. A., Runia, W. T., Termorshuizen, A. J., Feil, H., and van der Wurff, A. W. 2014. Anaerobic soil disinfestation in microcosms of two sandy soils. Commun. Agric. Appl. Sci. 79:15-19.

Sundin, G. W., Werner, N. A., Yoder, K. S., and Aldwinckle, H. S. 2009. Field evaluation of biological control of fire blight in the eastern United States. Plant Dis. 93:386-394.

Timm, C. M., Campbell, A. G., Uttukar, S. M., Jun, S.-R., Parales, R. E., Tan, W. A., Robeson, M. S., Lu, T. S., Jawdy, S., Brown, S. D., Ussery, D. W., Schadt, C. W., Tuskan, G. A., Doktycz, M. J., Weston, D. J., and Pelletier, D. A. 2015. Metabolic functions of Pseudomonas fluorescens strains from Populus deltoides rhizosphere and endosphere isolation compartment. Front. Microbiol. 6:1118. 
United Nations Environment Programme. 2012. Handbook for the Montreal Protocol on Substances that Deplete the Ozone Layer, 9th ed. Published online. http://ozone.unep.org/Publications/MP_Handbook/MP-Handbook-2012.pdf

United States Department of State. 2014. Methyl Bromide Critical Use Nomination for Preplant Soil Use for Strawberry Fruit Grown in Open Fields (Submitted in 2014 for the 2016 Use Season), Washington, D.C.

Van Bruggen, A. H. C., and Finckh, M. R. 2016. Plant diseases and management approaches in organic farming systems. Annu. Rev. Plant Pathol. 54:25-54.

van der Voort, M., Kempenaar, M., van Driel, M., Raaijmakers, J. M., and Mendes, R. 2016. Impact of soil heat on reassembly of bacterial communities in the rhizosphere microbiome and plant disease suppression. Ecol. Lett. 19:375-382.

van Lenteren, J. C., Babendreier, D., Bigler, F., Burgio, G., Hokkanen, H. M. T., Kuske, S., Loomans, A. J. M., Menzler-Hokkanen, I., van Rijn, P. C. J., Thomas, M. B., Tommasini, M. G., and Zeng, Q.-Q. 2003. Environmental risk assessment of exotic natural enemies used in inundative biological control. BioControl 48:3-38.

Vida, C., Bonilla, N., de Vicente, A., and Cazoria, F. M. 2016. Microbial profiling of a suppressiveness-induced agricultural soil amended with composted almond shells. Front. Microbiol. 7:4.

Von Felten, Défago, G., and Maurhofer, M. 2010. Quantification of Pseudomonas fluorescens strains F113, CHA0 and Pf153 in the rhizosphere of maize by strain-specific real-time PCR unaffected by the variable of DNA extraction efficiency. J. Microbiol. Methods 81:108-115.

Weerakoon, D. M. N., Reardon, C. L., Paulitz, T. C., Izzo, A. D., and Mazzola, M. 2012. Long-term suppression of Pythium abappressorium induced by
Brassica juncea seed meal amendment is biologically mediated. Soil Biol. Biochem. 51:44-52.

Wei, Z., Yang, X., Yin, S., Shen, Q., Ran, W., and Xu, Y. 2011. Efficacy of Bacillus-fortified organic fertiliser in controlling bacterial wilt of tomato in the field. Appl. Soil Ecol. 48:152-159.

Weller, D. M. 1988. Biological control of soil borne plant pathogens in the rhizosphere with bacteria. Annu. Rev. Phytopathol. 26:379-407.

Weller, D. M., Raaijmakers, J. M., McSpadden Gardner, B. B., and Thomashow, L. S. 2002. Microbial populations responsible for specific soil suppressiveness to plant pathogens. Annu. Rev. Phytopathol. 40:309-348.

Widder, S., Allen, R. J., Pfeiffer, T., Curtis, T. P., Wiuf, C., Sloan, W. T., Cordero, O. X., Brown, S. P., Momeni, B., Shou, W., Kettle, H., Flint, H. J., Haas, A. F., Laroche, B., Kreft, J.-U., Rainey, P. B., Freilich, S., Schuster, S., Milferstedt, K., van der Meer, J. R., Großkop, T., Huisman, J., Free, A., Picioreanu, C., Quince, C., Klapper, I., Labarthe, S., Smets, B. F., Wang, H., and Soyer, O. S. 2016. Challenges in microbial ecology: building predictive understanding of community function and dynamics. ISME J. 10:2557-2568.

Xu, X. M., Jeffries, P., Pautasso, M., and Jeger, M. J. 2011. Combined use of biocontrol agents to manage plant diseases in theory and practice. Phytopathology 101:1024-1031.

Yuliar, Nion, Y. A., and Toyota, K. 2015. Recent trends in control methods for bacterial wilt diseases caused by Ralstonia solanacearum. Microbes Environ. 30:1-11.

Zelezniak, A., Andrejev, S., Ponomarova, O., Mende, D. R., Bork, P., and Patil, K. R. 2016. Metabolic dependencies drive species co-occurrence in diverse microbial communities. Proc. Natl. Acad. Sci. USA 112:6449-6454. 